\title{
Synchrotron-(XRF, XRD, XAFS) Techniques in Advanced Mineralogy
}

ISSN: 2578-0255

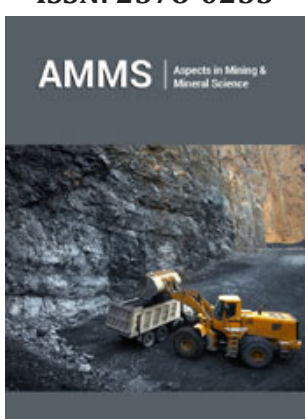

*Corresponding author: Nandini Garg, High Pressure and Synchrotron Radiation Physics Division, Bhabha Atomic Research Centre, Mumbai, India

Submission: 侮 May 22, 2020

Published: 䟧June 29, 2020

Volume 5 - Issue 2

How to cite this article: Lahiri D, Garg Nandini, Nayak BK. Synchrotron-(XRF, XRD, XAFS) Techniques in Advanced Mineralogy. Aspects Min Miner Sci. 5(2). AMMS.000606. 2020.

DOI: 10.31031/AMMS.2020.05.000606

Copyright@ Garg Nandini, This article is distributed under the terms of the Creative Commons Attribution 4.0 International License, which permits unrestricted use and redistribution provided that the original author and source are credited.

\author{
Lahiri $\mathrm{D}^{1}$, Garg Nandini ${ }^{1 *}$ and Nayak BK ${ }^{1,2}$ \\ ${ }^{1}$ High Pressure and Synchrotron Radiation Physics Division, Bhabha Atomic Research Centre, \\ India \\ ${ }^{2}$ Homi Bhabha National Institute, Training School Complex, India
}

\begin{abstract}
Advent of high-intense x-ray synchrotrons has significantly empowered detection capabilities and stimulated diverse atomic-scale characterization experiments with wide application spectrum extending to under-explored fields such as structural biology and environment. We review the utilization of synchrotron-based techniques (XRF, XRD, XAFS) in mineralogy. While (XRF, XRD) are more regularly employed for basic speciation of minerals, the exploitation of versatile XAFS technique to address advanced problems in mineralogy is clearly limited. We suggest a host of advanced problems that could be addressed by these techniques and should inspire ambitious research for advancing the scope of mineralogy in future.
\end{abstract}

Keywords: XAFS; XRF; XRD; Minerals; Synchrotron

\section{Introduction}

X-ray and electron probe-based characterizations of minerals have traditionally addressed scientific problems of micro- and macro- length scales [1]. However, recent advancements in mineral applications e.g. nano-drugs [2], novel functional materials [3-5] demand nano-scale characterization for better understanding and control of this field. In this article, we review the scope of synchrotron-based x-ray techniques [XRF, XRD, XAFS] to address this requirement. The advantage of synchrotron-based research approach derives from (i) high $\mathrm{x}$-ray flux (10 $10^{11-}$ ${ }^{14} \mathrm{ph} / \mathrm{s}$ ), enabling the detection of elements in ppm concentrations; (ii) wide energy spectrum (5-30keV) covering the binding energies of all elements and enabling their detection; (iii) short wavelengths $(0.5-2.5 \AA)$ to probe atomic length-scale phenomena. Synchrotrons around the world are listed in [6]. All of these techniques are non-destructive and undemanding wrt sample requirements. Laboratory-based XRF is widely employed in mineralogy for elemental speciation and XRD for characterization of crystalline phases and detection of crystallineamorphous phase transitions. These techniques are significantly empowered by synchrotron as detection limits are extended towards dilute hidden phases. Advanced scientific problems can be addressed with (relatively recent) versatile XAFS technique [7], that reveals chemical state of any selected element in the material and structural information within $10 \AA$ of the element. Unique advantages of XAFS are (i) simultaneous structural and chemical information, (ii) detection of ppm elemental concentrations, (iii) sensitivity to amorphous structure (e.g. liquid, glass, soil), (iv) site-resolved information (e.g. structure around dilute dopants). (XRF, $\mathrm{XRD}, \mathrm{XAFS}$ ) in conjunction can provide the most comprehensive information for any mineral. We review the present utilization and future scope of these techniques in mineralogy.

\section{Application}

Many current works are limited to basic speciation [8-11]. Advanced problems include bioavailability of essential minerals [12], remediation of toxic contaminated soil $[13,14]$, fuel 
behavior in reactors and synthesis of novel catalysts [15]. These studies reveal correlation between (oxidation state/bond-length) parameters and (mobility/solubility/sorption), with implications for reclamation/remediation/reactor technology. Our recent investigation of gadolinite revealed the role of structural disorder in flexible accommodation of radioactive waste. These citations cover the current utilization range of these techniques in mineralogy, which is clearly limited. Future role of these techniques lies in guiding the development of mineral nano-drugs [16] and mineral extraction nanotechnology $[17,18]$. Advanced adaptations of these techniques e.g. structure-pressure correlation from High Pressure(XRD, XAFS) could be exploited to locate minerals beneath earth [19]. Magnetic measurement with XAFS-based "X-ray Magnetic Circular Dichroism" (XMCD) technique [20] should be envisaged to explore novel magnetic materials. These novel problems will greatly advance the scope of mineralogy.

\section{Conclusion}

The review reveals the comprehensive potential of synchrotronbased (XRF, XRD, XAFS) techniques for nano-scale characterization, which is clearly under-utilized in mineralogy. Their current utilization in mineralogy is limited mostly to basic speciation of minerals and a few advanced problems with implications for mineral reclamation/ soil remediation/ waste immobilization technologies. We suggest a host of novel problems that can be undertaken by these techniques and that can broaden the scope of mineralogy significantly.

\section{References}

1. Melgarejo JC, Proenza JA, Gali S, Llovet X (2010) Techniques of mineral characterization and their use in mining exploration and exploitation. Boletin de la Sociedad Geologica Mexicana 62(1): 1-23.

2. Raje K, Ojha S, Mishra A, Munde VK, Rawat C, et al. (2018) Impact of supplementation of mineral nanoparticles on growth performance and health status of animals: A review. J Entomol Zool Stud 6(3): 1690-1694.

3. Lu Y, Dong W, Wang W, Ding J, Wang Q, et al. (2018) Optimal synthesis of environment-friendly iron red pigment from natural nanostructured clay minerals. Nanomaterials 8(11): 925.

4. Krivovichev SV, Yakovenchuk VN, Zhitova ES (2011) Natural double layered hydroxides: structure, chemistry, and information storage capacity. Minerals as Advanced Materials II pp. 87-102.

5. Balaram V (2019) Rare earth elements: A review of applications, occurrence, exploration, analysis, recycling, and environmental impact. Geosci Front 10: 1285-1303.
6. https://www.lightsources.org

7. Koningsberger DC, Prins R (1988) X-ray absorption: principles, applications, techniques of EXAFS, SEXAFS and XANES. John Wiley, New York.

8. Sugiyama K, Arima H, Konno H, Mikouchi T (2017) XAFS study on the location of $\mathrm{Cu}$ and $\mathrm{Mn}$ in a greenish blue elbaite from Alto dos Quntos mine, Brazil. J Miner Petrol Sci 112: 139-146.

9. Baker LL, Strawn DG, Vaughan KL, Mcdaniel PA (2012) XAS study of Fe mineralogy in a chronosequence of soil clays formed in basaltic cinders. Clay Clay Miner 58(6): 772-782.

10. Okudera H, Yoshiasa A, Murai K, Okube M, Takeda T, et al. (2012) Local structure of magnetite and maghemite and chemical shift in Fe K-edge XANES. J Miner Petrol Sci 107(3): 127-132.

11. Henderson CMB, Charnock JM, Cressey G, Griffen DT (1997) An EXAFS study of the local structural environments of $\mathrm{Fe}, \mathrm{Co}, \mathrm{Zn}$ and $\mathrm{Mg}$ in natural and synthetic staurolites. Mineral Mag 61(408): 613-625.

12. Wichard T, Mishra B, Myneni SCB, Bellenger JP, Kraepiel AML, et al. (2009) Storage and bioavailability of molybdenum in soils increased by organic matter complexation. Nat Geosci 2: 625-629.

13. Catalano JG, Heald SM, Zachara JM, Brown GE (2004) Spectroscopic and diffraction study of uranium speciation in contaminated vadose zone sediments from the Hanford Site, Washington State. Environ Sci Technol 38(10): 2822-2828.

14. Suzuki Y, Kelly SD, Kemner KM, Banfield JF (2002) Nanometre-size products of uranium bioreduction. Nature 419(6903): 134.

15. Misra NL, Lahiri D, Mudher KDS, Olivi L, Sharma SM (2008) XANES study on novel mixed valent $\mathrm{A}_{2} \mathrm{U}_{4} \mathrm{O}_{12}(\mathrm{~A}=\mathrm{K}, \mathrm{Rb}$ or $\mathrm{Tl})$ uranates. X-Ray Spectrom 37(3): 215-218.

16. Ramanan N, Lahiri D, Rajput P, Varma RC, Arun A, et al. (2015) Investigating structural aspects to understand the putative/claimed non-toxicity of the Hg-based ayurvedic drug rasasindura using XAFS. J Synchrotron Rad 22(5): 1233-1241.

17. https://nano-magazine.com/news/2019/4/27/nanotechnologys-potential-in-the-mining-industry.

18. Lahiri D, Sharma SN, Zeena S, Bunker BA (2005) Evidence for the chemical nature of capping in CdSe nanoparticles. J Surface Sci Technol 21(12): 11-22.

19. Lahiri D, Dwivedi A, Vasanthi R, Jha SN, Garg N (2020) First high pressure XAFS results at bending magnet-based energy dispersive XAFS beamline (BL-8), Indus2 synchrotron facility (India). J Synchrotron Rad 27: 988-998.

20. Pattrick RAD, Van der Lann G, Henderson C, Michael B (2002) Cation site occupancy in spinel ferrites studied by X-ray magnetic circular dichroism: developing a method for mineralogists. Eur J Mineral 14(6): 1095-1102. 